\title{
Middle ear cholesteatoma otitis after grommet insertion
}

\author{
Otită medie colesteatomatoasă după aerator transtimpanal
}

\author{
Adina Zamfir-Chiru-Anton' ${ }^{1}$ Alexandru Ulici' ${ }^{1}$, Valeria Vlăsceanu ${ }^{1}$, \\ Mădălina Georgescu ${ }^{3}$, Dan Cristian Gheorghe ${ }^{2}$ \\ ${ }^{1}$ Spitalul Clinic de Urgenţă pentru Copii „Grigore Alexandrescu“, Bucureşti, România \\ ${ }^{2}$ Spitalul Clinic de Urgenţă pentru Copii „M.S. Curie“, Bucureşti, România \\ ${ }^{3}$ Institutul de Fonoaudiologie şi Chirurgie Funcţională ORL, Bucureşti, România
}

\begin{abstract}
Objective. Presenting a rare case of middle ear cholesteatoma, possible as a result of grommet insertion. The disease occured a few months after tympanostomy tube spontaneous extrusion. The Shepard tube was used to manage suppurative recurrent otitis media persisting after adenoidectomy.

Material, method. Otoscopic examination of the eardrum, mastoidectomy, cartilage graft miringoplasty. Results. The patient needed surgery for removal of cholesteatoma from the middle ear and tympanic membrane reconstruction using tragal cartilage with pericondrium.

Conclusions. Cholesteatoma can occur after tympanostomy tube insertion. Its incidence is very low but it should be presented as a possible complication to the patient. Precise technique for grommet insertion could prevent the disease.
\end{abstract}

Keywords: middle ear cholesteatoma, otitis, tympanoplasty, grommet

\section{REZUMAT}

Obiective. Punerea în discuţie a unui caz clinic rar de depistare a colesteatomului, posibil iatrogen, la nivelul urechii medii. Afecţiunea pare a fi instalată la câteva luni de la eliminarea în mod natural a unui tub de ventilaţie tip Shepard, montat ca metodă terapeutică pentru frecvente otite medii supurate (ajunse până în stadiul preperforativ), în ciuda adenoidectomiei.

Material şi metodă. Examen otomicroscopic, mastoidectomie şi aticotomie externă transmetală cu ridicarea colesteatomului, urmată de miringoplastie cu cartilaj tragal.

Rezultate. Pacienta a beneficiat de ablaţia colesteatomatomului de la nivelul urechii medii prin aticotomie transmeatală, precum şi de tratamentul pungilor de retracţie de la nivelul timpanului printr-o miringoplastie cu cartilaj tragal.

Concluzii. Colesteatomul poate fi rezultatul unei timpanostomii. Cazurile sunt foarte rare, dar trebuie prezentate pacientului ca fiind posibile complicaţii. Respectarea unei tehnici precise de timpanostomie este necesară pentru prevenţie.

Cuvinte cheie: colesteatom de ureche medie, otită, miringoplastie, diabolo

\section{INTRODUCERE}

Colesteatomul urechii medii este o afecțiune frecventă şi ridică atât probleme de diagnostic, cât şi de tratament. Cauzele apariţiei afecțiunii pot fi multiple (1). În funcție de mecanismul patogenic, colesteatoamele au fost clasificate în boli congenitale sau dobândite (2). La rândul lor, cele din cea de-a doua categorie pot fi produse de factori intrin- seci, legați de particularități anatomice şi individuale, sau de către factori externi, cel mai frecvent traumatici sau iatrogeni.

Colesteatomul urechii medii este, în esență, o incluziune epidermică în zone care altfel sunt tapetate doar de mucoasă. Pungile de retracție privite ca un prim pas către acest proces sunt consecința presiunii negative din urechea medie (descris de $\mathrm{M}$. Tos). Din zonele retractate ale membranei timpani- 
ce apare o proliferare epitelială de la nivelul stratului extern. Acest proces este explicat prin ruperea echilibrului dintre multiplicarea celulară şi exfolierea epidermică.

O cauză mai rară de colesteatom dobândit o constituie inserția aeratorului transtimpanal (3). Ruptura barierei epidermice a timpanului şi cicatrizarea defectuasă a acestuia sunt elemente care contribuie la patogenie.

\section{PREZENTARE DE CAZ}

Un copil în vârstă de trei ani şi opt luni, cunoscut clinicii cu multiple afectiuni otice drepte, se internează pentru otoree rebelă la tratament şi hipoacuzie.

Copilul prezintă în istoric multiple otite medii supurate acute, diagnosticate în fază preperforativă, pentru care s-a decis efectuarea adenoidectomiei sub anestezie generală. S-a decis şi utilizat simultan cu adenoidectomia un tub de aerație transtimpanic, de tip Shepard. Episoadele de otită supurată au continuat să recidiveze, dar cu o frecvență şi agresivitate mult mai reduse după adenoidectomie. Simptomul în acest caz a fost otoreea recurentă.

După aproximativ 8 luni, aeratorul transtimpanal a fost eliminat spontan.

Afecțiunea actuală a debutat în urmă cu trei săptămâni, prin otoree şi hipoacuzie, pentru care a urmat un tratament cu antibiotic (cefalosporină), antiinflamator, dezobstrucție nasofaringiană (instilații nazale cu vasoconstrictor). În secreția otică, pe lângă germeni sensibili la cefalosporine (Streptococus pneumoniae), s-a identificat şi Candida albicans, pentru care s-a administrat un antimicotic local (clotrimazol). În ciuda tratamentului, simptomatologia nu s-a remis complet, otoreea a persistat. S-a efectuat o audiogramă care a evidențiat o hipoacuzie de transmisie uşoară, cu un ABG de 30-40 db pe frecvențele de 125, 250 şi $500 \mathrm{~Hz}$.

Se decide internarea cu efectuarea examenului otomicroscopic sub AG, care decelează o pungă de retracție anterioară, cu o breşă minimală a epidermului timpanic, prin care se exteriorizează lamele albicioase, alb-sidefii, specifice unui colesteatom.

Examenul computer tomograf confirmă prezența unor țesuturi moi ce umplu urechea medie şi cavităţile mastoidiene (Fig. 1).

Sub anestezie generală, se practică deschiderea cavităților otomastoidiene pentru verificarea posibilei prezențe a unui colesteatom în zonele respective. Prezența unui țesut de granulație abundent atestă lipsa de aerație a procesului mastoid al osului temporal.

Deschiderea urechii medii arată existența unei aderențe importante a epidemului la nivelul promontoriului, în dreptul fostului sediu de amplasare al aeratorului transtimpanic. Punga de retracție umple complet spațiul urechii medii şi blochează orificiul tubar în totalitate. După eliminarea completă a epidermului şi eliberarea protimpanului de formațiunea epidermică, se practică miringoplastie cu cartilaj concal. Lanțul osicular este păstrat integru.

Postoperator, evoluția esta favorabilă, iar conservarea auzului bună, lanțul osicular nefiind interesat de procesul osteolitic.

\section{DISCUŢII}

Colesteatomul urechii medii poate fi congenital sau dobândit prin evoluția spontană a unei pungi de retracție timpanice. Clasificarea şi atitudinea chirurgicală față de aceasta nu este standardizată şi cu rezultate uniforme (4).
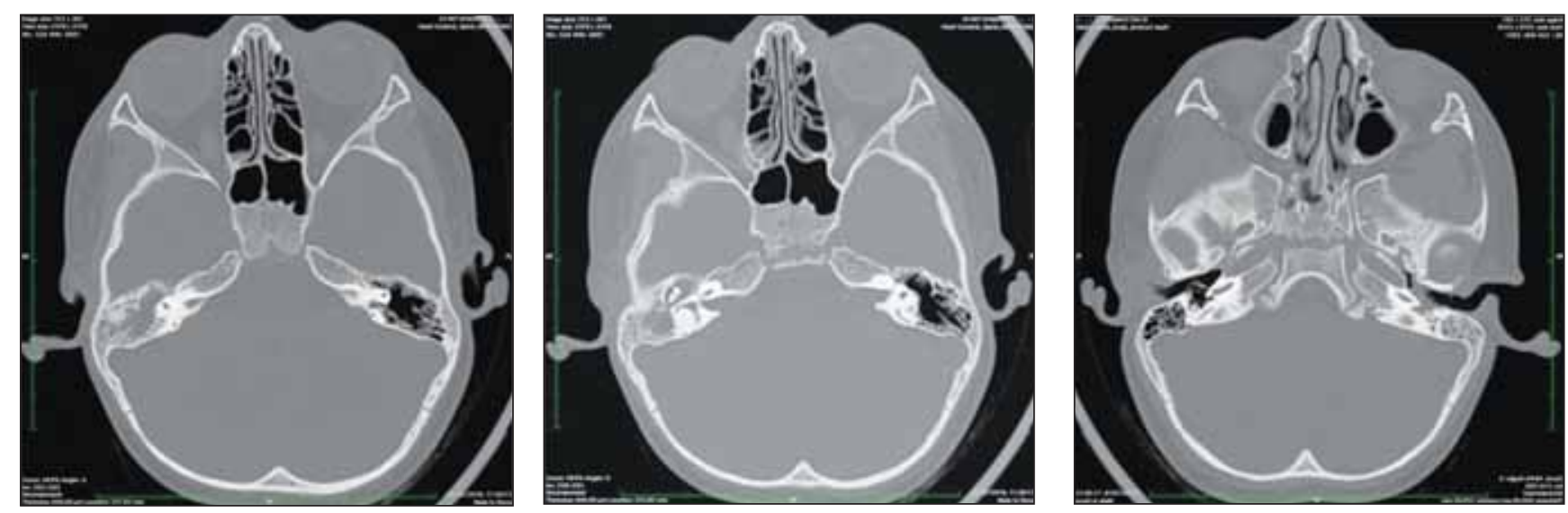

FIGURA 1. Aspect CT preoperator: ureche medie şi cavități mastoidiene pline cu țesut moale; discretă liză septală mastoidiană 
Colesteatoame după aplicarea tuburilor de ventilație timpanică au mai fost descrise (5). Asupra incidenței acestora există însă controverse (6). Folosirea tuburilor de ventilație a fost aleasă pentru prevenția retracțiilor timpanice, motiv pentru care este greu de explicat patogenia colesteatomului în asemenea cazuri (7).

În epidermul normal al membranei timpanice nu există celule Langerhans (macrofage cu proprietăți biologice şi metabolice), dar ele sunt prezente la nivelul pungilor de retracție fixate. Ele îşi schimbă activitatea şi caracteristicile biologice în momentul contactului dintre epidermul membranei timpanice şi mucoasa sau țesutul conjunctiv al urechii medii. Între epidermul migrat şi țesutul conjunctiv se creează o reacție inflamatorie de tip imunologic autoîntreținut (la contactul celulelor Langerhans cu cheratinocitele şi limfocitele T) (1). Astfel, se explică existența unui număr foarte mare de celule Langerhans şi gruparea lor la nivele diferite ale stratului epidermic bazal, suprabazal şi la nivelului corionului subiacent, în matricea (periferia) colesteatomului.

La copil, colesteatomul prezintă un caracter agresiv şi extensia mai rapidă la nivelul cavităţilor urechii medii. Fenomenul este stimulat posibil de reacțiile inflamatorii şi infecțiile frecvente, propagate prin trompa lui Eustache. Disfuncția tubară de diverse cauze, din aceeaşi perioadă, explică apariției recidivelor frecvente. Extinderea leziunilor colesteatomatoase poate lua aspect digitiform, cu reacție granulomatoasă perimatriceală intens reprezentată, fenomen stimulat inițial de o insuficiență tubară anatomică, apoi de blocajul trompei prin însăşi procesul colesteatomatos (8).

Tehnicile chirurgicale de eradicare ale colesteatomului sunt variate. Unii autori insistă pe efectuarea unor intervenții minime, conduse de extensia intratemporală a colesteatomului şi urmate de reconstrucții miringo-osiculare $(9,10)$.

Reconstrucția membranei timpanice şi a lanţului osicular trebuie să prevină factorii care au fost la geneza iniţială a bolii: disfuncția tubară şi calitatea slabă a membranei timpanice (secundară inflamației sau traumatismului). Prezervarea spațiului urechii medii şi consolidarea membranei timpanice, cu ajutorul grefelor compozite, scade la minimum şansele de recidivă a retracțiilor timpanice (11).

În cazul prezentat, amplasarea tubului de ventilație a asigurat aerarea urechii medii şi o evoluție clinic favorabilă. Acest lucru a determinat o prezentabilitate minimă la medicul curant, permițând apariția complicațiilor.
Descoperirea prin examen otomicroscopic (sub anestezie generală) a unui epiderm aderent la peretele medial al urechii medii, tardiv după eliminarea tubului, pe locul de elecție al timpanostomiei, duce, evident, la ipoteza retracției şi lipirii membranei timpanice la mucoasa subiacentă, cu crearea unei pungi de retracție localizate. Monitorizarea acestor pungi poate constitui diferența dintre o leziune uşor controlabilă, benignă, şi colesteatom, leziune potențial distructivă pentru conținutul urechii medii. Dificultățile acestui caz provin din:

- Lipsa de cooperare a pacientului pentru un examen detaliat al membranei timpanice (în absența anesteziei generale);

- Neprezentarea periodică la medic pentru monitorizare, în prezența unui trecut otologic cunoscut.

Variantele de tratament pentru cazul de faţă includ:

- lărgirea orificiului pungii de retracție, cu vizualizarea completă a epidermului constitutiv şi monitorizare constantă;

- extirparea chirurgicală a elementelor epidermice, în cazul în care există scuame macerate ce nu pot fi drenate din interiorul pungii de retracție.

Prevenția recidivelor colesteatomatoase înseamnă asigurarea unei buni aerări a urechii medii, prin îndepărtarea oricăror obstacole anatomice din protimpan şi întărirea membranei timpanice prin grefe compozite (cartilaj-pericondru).

Patogenia leziunii în cazul tuburilor de ventilație poate presupune mai mulți factori implicați: ruperea necontrolată a timpanului, cu crearea ad-hoc a unui lambou voluminos, flotant. Inversarea sa către urechea medie poate duce la aderențe la mucoasa locală. Disfuncția trompei Eustache concomitentă favorizează presiunea negativă din urechea medie şi evolutivitatea locală a retracției iniţiale. Dacă punga epidermică evoluează anatomic spre orificiul tubar din urechea medie, atunci se închide un cerc vicios, cu blocarea definitivă a aerisirii urechii medii şi agravarea constantă a leziunilor.

\section{CONCLUZII}

În cazul prezentat, am concluzionat că formarea colesteatomului a fost posibilă, pe de-o parte, prin disfuncția tubară persistentă chiar şi după adenoidectomie, dar şi printr-o soluție de continuitate a membranei timpanice efectuată iatrogen. Incizia insuficientă a membranei timpanice, permițând răsfrângerea marginilor acesteia către urechea medie 
odată cu inserția tubului de ventilație, poate explica geneza acestei boli la cazul prezentat. În acest mod, se poate facilita contactul epiteliului timpanul cu mucoasa urechii medii, aderențele locale şi proliferarea ulterioară a epidermului în urechea medie.

Deşi foarte rare, raportat la frecvența mare de utilizare a aeratoarelor transtimpanice, colesteatoa-

\section{BIBLIOGRAFIE}

1. Welkoborsky H.J. (Current concepts of the pathogenesis of acquired middle ear cholesteatoma). Laryngorhinootologie, 2011. 90(1): p. 38-48; quiz 49-50.

2. Nevoux J. et al. Childhood cholesteatoma. European annals of otorhinolaryngology, head and neck diseases, 2010. 127(4): p. 143-50.

3. Spilsbury K. et al. Factors associated with developing cholesteatoma: a study of 45,980 children with middle ear disease. Laryngoscope, 2010. 120(3): p. 625-30.

4. Alzahrani M., I. Saliba. Tympanic membrane retraction pocket staging: is it worthwhile? European Archives of Oto-RhinoLaryngology, 2014. 271(6): p. 1361-1368.

5. Golz A. et al. Cholesteatomas associated with ventilation tube insertion. Arch Otolaryngol Head Neck Surg, 1999. 125(7): p. 754-7.

6. Cherry J.R. Paediatric ENT surgery. Grommets and cholesteatoma. BMJ, 2011. 342: p. d647. mele iatrogene reprezintă o patologie de temut care necesită recunoştere şi intervenție corectoare precoce, pentru prevenția leziunilor severe ale lanțului osicular şi hipoacuzii consecutive.

Notă. Toți autorii au participat în mod egal la redactarea acestei lucrări.

Conflict of interest: none declared Financial support: none declared

7. Cassano M., P. Cassano. Retraction pockets of pars tensa in pediatric patients: clinical evolution and treatment. Int J Pediatr Otorhinolaryngol, 2010. 74(2): p. 178-82.

8. Sim M.W. et al. Congenital cholesteatoma involving the Eustachian tube. Int J Pediatr Otorhinolaryngol, 2011. 75(4): p. 600-2.

9. Roth T.N. et al. Cholesteatoma surgery in children: long-term results of the inside-out technique. Int J Pediatr Otorhinolaryngol, 2013. 77(5): p. 843-6.

10. Ramakrishnan A. et al. Cortical mastoidectomy in surgery of tubotympanic disease. Are we overdoing it? Surgeon, 2011. 9(1): p. 22-6.

11. Shinnabe A. et al. Relationship between postoperative aeration around the stapes and postoperative hearing outcome after canal wall down tympanoplasty with canal reconstruction for cholesteatoma. Otol Neurotol, 2011. 32(8): p. 1230-3. 